\title{
Cianobactérias planctônicas de um lago artificial urbano na cidade de Goiânia, GO
}

\author{
INA DE SOUZA NOGUEIRA ${ }^{1,2}$, WATSON ARANTES GAMA JÚNIOR ${ }^{1} \mathrm{e}$ \\ EMMANUEL BEZERRA D'ALESSANDRO ${ }^{1}$
}

(recebido: 28 de julho de 2011; aceito: 24 de novembro de 2011

\begin{abstract}
Planktonic cyanobacteria from an artificial urban lake in the city of Goiânia, Goiás State). Fish farms are numerous in Goiás State and they are under intense recreational activity. However, studies about cyanobacteria in these environments are scarce, a concerning situation, since the occurrence of intense proliferation of phytoplankton in this kind of environments is common and there is the risk of blooms of toxic species. This paper aims to carry out the inventory of planktonic species of cyanobacteria occurring in a fishery pond (lake Jaó - a shallow artificial lake) in the city of Goiânia (16³9'13" S$\left.49^{\circ} 13^{\prime} 26^{\prime \prime} \mathrm{W}\right)$. Sampling was carried out during dry (2003 to 2008) and rainy periods (2009), when it was visually evident the occurrence of blooms. Climatic, morphometric and limnological variables were measured. The dry period was representative in the sampled years presenting a maximum of $50 \mathrm{~mm}$ of monthly precipitation in 2005 . Thirty-one taxa of cyanobacteria were found belonging to the genera Dolichospermum (5 spp.), Aphanocapsa (4 spp.), Microcystis (3 spp.), Pseudanabaena (3 spp.), Radiocystis (2 spp.), Oscillatoria (2 spp.), and Bacularia, Coelosphaerium, Cylindrospermopsis, Geitlerinema, Glaucospira, Limnothrix, Pannus, Phormidium, Planktolyngbya, Planktothrix, Sphaerocavum and Synechocystis with one species each. In the years of 2003 to 2005 the blooms were formed predominantly by species of Dolichospermum and in 2006 by species of Microcystis, Radiocystis and Aphanocapsa. Among all the species identified in this study, 21 are new records for the state and 13 have been referenced in literature as potentially toxic.
\end{abstract}

Key words - Aphanocapsa, Dolichospermum, fish farm, Microcystis

RESUMO - (Cianobactérias planctônicas de um lago artificial urbano na cidade de Goiânia, GO). Os criatórios de peixe do estado de Goiás são inúmeros e de intensa atividade recreativa. No entanto, estudos sobre as cianobactérias nesses ambientes são escassos, fato preocupante, uma vez que é comum notar-se intensa proliferação do fitoplâncton em pesqueiros, principalmente devido a ações antrópicas. O perigo consiste na formação de florações de espécies potencialmente tóxicas, principalmente de cianobactérias. Este trabalho visa inventariar as espécies planctônicas de cianobactérias ocorrentes em um pesqueiro (lago Jaó - um lago artificial raso) da área municipal de Goiânia (GO) (16³9’13" S-49¹3’26" O). As amostragens foram realizadas nos períodos de seca (2003 a 2008) e chuva (2009), quando visualmente era evidente a ocorrência de florações. Foram aferidas variáveis climatológicas, morfométricas e limnológicas. O período de seca foi representativo nos anos amostrados apresentando no máximo $50 \mathrm{~mm}$ de precipitação mensal em 2005. Foram registrados 31 táxons de cianobactérias pertencentes aos gêneros Dolichospermum (5 spp.), Aphanocapsa (4 spp.), Microcystis (3 spp.), Pseudanabaena (3 spp.), Radiocystis (2 spp.), Oscillatoria (2 spp.), Bacularia, Coelosphaerium, Cylindrospermopsis, Geitlerinema, Glaucospira, Limnothrix, Pannus, Phormidium, Planktolyngbya, Planktothrix, Sphaerocavum e Synechocystis, esses últimos com uma espécie cada. Nos anos de 2003 a 2005 ocorreu predomínio de florações de espécies de Dolichospermum e em 2006 predominaram espécies de Microcystis, Radiocystis e Aphanocapsa. Das espécies inventariadas neste estudo, 21 são primeiras citações para o estado de Goiás e 13 foram constadas na literatura como potencialmente tóxicas.

Palavras-chave - Aphanocapsa, Dolichospermum, Microcystis, pesqueiro

\section{Introdução}

A proliferação de algas e cianobactérias acontece, na maioria dos casos, devido ao enriquecimento artificial por nutrientes, principalmente fosfatados e nitrogenados (Veraart et al. 2008). Ambientes

\footnotetext{
1. Universidade Federal de Goiás, Instituto de Ciências Biológicas, Laboratório de Análise e Gerenciamento Ambiental de Recursos Hídricos - AMARH, Caixa Postal 131, Campus II, 74001-970 Goiânia, GO, Brasil.

2. Autor para correspondência: nogueira@icb.ufg.br
}

que comumente apresentam massiva quantidade de microalgas são tanques, represas e lagos destinados à cultura de organismos aquáticos (crustáceos, peixes etc.), principalmente pelo tipo de alimentação utilizada para manter os criadouros (Kubtiza 2003). Um agravante é quando tais corpos hídricos se localizam em zona urbana, o que pode fornecer mais fontes de nutrientes e incrementar o processo de eutrofização (Tundisi \& Matsumura-Tundisi 2008).

As condições climáticas e hídricas do estado de Goiás se mostram propícias à instalação desses ambientes. Em Goiânia, são vários os parques ambientais, sendo que 
praticamente todos possuem ao menos um lago artificial (Nogueira et al. 2008). Além disso, a instalação de inúmeros pesqueiros é resultado do bom retorno financeiro gerado aos proprietários (Kitamura et al. 1999). Todavia, não há no Estado, e no Brasil, uma fiscalização efetiva que controle ou proíba o funcionamento de pesqueiros que apresentem riscos aos usuários. Já foi registrado acúmulo de cianotoxinas na musculatura de peixes (Magalhães et al. 2001) e há comprovação de que, em longo prazo, neurotoxinas e hepatotoxinas podem gerar tumores e cânceres em mamíferos, incluindo humanos (Apeldoorn et al. 2007).

Assim, torna-se necessário o conhecimento das espécies de cianobactérias que se desenvolvem nos pesqueiros para que medidas mais efetivas possam ser tomadas, sendo extremamente escassos os trabalhos com este objetivo. O artigo de Matsuzaki et al. (2004) mostra que as cianobactérias não formaram o grupo com a maior riqueza de espécies em um pesqueiro, porém várias das espécies encontradas são potencialmente tóxicas e podem levar riscos à saúde pública. Além disso, Hoffmann (1996) ressalta a importância dos inventários florísticos para a construção de um cenário de distribuição desses organismos, principalmente para a região tropical.

No Estado de Goiás, ainda, são poucos os estudos sobre a flora de cianobactérias, resumindo-se aos seguintes trabalhos: Drouet (1957), Prescott (1957), Campos \& Macedo-Saidah (1990), Campos et al. (1990), Crispin et al. (1992), Contin \& Oliveira (1993), Nascimento-Bessa \& Santos (1995), Saneago (1996), Brandão \& Kravchenko (1997), Bazza (1998), Nogueira \& Leandro-Rodrigues (1999), Silva et al. (2001), Nogueira et al. (2002), Pivato et al. (2006), Nardini \& Nogueira (2008) e Nogueira et al. (2008).

Dessa forma, o presente trabalho visa inventariar as espécies de cianobactérias planctônicas ocorrentes em um lago artificial na área municipal de Goiânia utilizado como pesqueiro.

\section{Material e métodos}

O lago Jaó é um lago artificial raso localizado no setor Jaó, região nordeste do município de Goiânia (GO) (16³9'13" S$\left.49^{\circ} 13^{\prime} 26^{\prime} \mathrm{O}\right)$. Atualmente é um ambiente destinado à criação de peixes, principalmente os popularmente conhecidos como pirarucu, pintado, dourado, caranha, tucunaré, matrinchã e piau. A pesca é a atividade mais comum e frequente no lago, sendo proibida qualquer forma de balneabilidade.

As amostragens foram realizadas nos períodos de seca (abril, maio, julho, agosto e setembro) de 2003 a 2008 e de chuva (novembro) de 2009, durante as florações. Ao todo, 13 amostras qualitativas, a priori analisadas vivas e, posteriormente, fixadas com solução de Transeau 1:1 (Bicudo \& Menezes 2006), e oito quantitativas fixadas com lugol acético 5\% (Vollenweider 1974) foram coletadas. Os valores de pluviosidade mensal da região estudada foram obtidos na Secretaria de Ciência e Tecnologia do Estado de Goiás (SECTEC). Foram analisadas as seguintes variáveis limnológicas: $\mathrm{pH}$ (potenciômetro Digimed), oxigênio dissolvido (método de Winkler - Golterman et al. 1978), temperatura (termístor Micronal), transparência da água (disco de Secchi), ortofosfato, nitrogênio total (métodos padronizados - Clesceri et al. 1992), condutividade (condutivímetro Micronal) e profundidade (corda metrificada).

As coletas foram realizadas em pontos aleatórios durante todos os anos amostrados, com o objetivo de se amostrar a maior área possível do lago. O material para análise qualitativa foi obtido através de filtração da água coletada na superfície por rede de plâncton de $25 \mu \mathrm{m}$ de abertura de malha. As amostras quantitativas foram coletadas a cerca de $10 \mathrm{~cm}$ da lâmina d'água e imediatamente fixadas, correspondendo apenas aos anos de 2003 a 2006. Nos anos subsequentes, somente foi analisado o material qualitativo. As amostras qualitativas foram depositadas no Herbário da Universidade Federal de Goiás (UFG).

As populações encontradas foram analisadas segundo as características morfológicas e morfométricas, sempre que possível avaliando-se a variabilidade dos caracteres. $\mathrm{O}$ material fresco foi observado para visualização da mobilidade e coloração dos espécimes.

As amostras foram quantificadas em microscópio óptico invertido Zeiss Axiovert 25, com aumento de 450x, conforme o método de Utermöhl (1958), a partir de campos distribuídos aleatoriamente (Ühelinger 1964). A quantificação dos organismos foi feita até alcançar 100 indivíduos (unicelulares, coloniais e filamentosos) da espécie mais frequente ou até estabilizar o número de espécies adicionadas por campo (área mínima de compensação). Desse modo o erro de contagem foi inferior a $20 \%$, em um nível de significância de 95\% (Lund et al. 1958). As espécies dominantes e abundantes foram definidas segundo Lobo \& Leighton (1986).

O sistema de classificação adotado para as cianobactérias foi o de Hoffmann et al. (2005) para nível hierárquico superior e igual à família. Para os níveis de gênero e espécie, utilizou-se a classificação proposta por Komárek \& Anagnostidis (1989, 1998, 2005). Utilizou-se bibliografia especializada para identificação das Cyanobacteria, destacando-se os seguintes trabalhos: Geitler (1932), Desikachary (1959), Komárek (1991), Komárková-Legnerová \& Eloranta (1992), Komárek \& Anagnostidis (1998, 2005), Sant'Anna \& Azevedo (2000), Komárek \& Komárková (2002), Sant'Anna et al. (2004, 2007), McGregor et al. (2007) e Wacklin et al. (2009). As espécies potencialmente tóxicas foram definidas segundo Sant'Anna et al. (2008) e Mohamed (2008).

Para os táxons são apresentadas descrições, comentários quando necessário, material examinado e distribuição geográfica apenas para o estado de Goiás. As abreviaturas 
usadas no texto são: compr. = comprimento; larg. = largura; diâm. = diâmetro; alt. = altura; espes. $=$ espessura. Os valores expressados entre parênteses correspondem a medidas raramente encontradas na população. Em relação aos tricomas espiralados, o diâmetro da espira foi medido em vista apical, desconsiderando-se a bainha.

\section{Resultados e discussão}

Durante a amostragem, os valores de precipitação mensal no período chuvoso foram acima de $200 \mathrm{~mm}$. Todavia, esse valor chegou a praticamente zero nos meses de agosto e setembro dos anos estudados.

O lago Jaó possui profundidade média de 2,1 metros e perímetro de 1.185 metros, sendo um ambiente artificial pequeno e raso. Devido às características climatológicas da região, o lago está constantemente exposto a altas temperaturas e incidências luminosas, o que somado ao enriquecimento artificial com nutrientes, o torna altamente propício a florações. Isso é revelado pelas características limnológicas, que mostram um pesqueiro com águas esverdeadas pouco transparentes, $\mathrm{pH}$ alcalino, elevados valores de oxigênio (até supersaturação) e temperatura da água acima de $25^{\circ} \mathrm{C}$ (tabela 1$)$.

Foram registrados 31 táxons de cianobactérias pertencentes aos gêneros Dolichospermum (5 spp.), Aphanocapsa (4 spp.), Microcystis (3 spp.), Pseudanabaena (3 spp.), Radiocystis (2 spp.),
Tabela 1. Amplitude das variáveis limnológicas encontradas nos pontos amostrados do Lago Jaó (Goiânia, GO).

Table 1. Range of limnological variables found in the sampled sites of Jaó Lake (Goiânia, GO).

\begin{tabular}{lcc}
\hline Variáveis & Máxima & Mínima \\
\hline Profundidade $(\mathrm{m})$ & 2,5 & 1,5 \\
Transparência $(\mathrm{m})$ & 0,5 & 0,4 \\
Temp. água $\left({ }^{\circ} \mathrm{C}\right)$ & 27,1 & 25,3 \\
Condutividade $\left(\mu \mathrm{S} \mathrm{cm}^{-1}\right)$ & 137,41 & 110,82 \\
$\mathrm{pH}$ & 9,1 & 7,5 \\
Sat. oxigênio $(\%)$ & 110,0 & 83,4 \\
Ortofosfato $\left(\mu \mathrm{g} \mathrm{L}^{-1}\right)$ & 81,4 & 54,0 \\
Nitrogênio total $\left(\mu \mathrm{g} \mathrm{L}^{-1}\right)$ & 289,1 & 112,0 \\
\hline
\end{tabular}

Oscillatoria (2 spp.), e Bacularia, Coelosphaerium, Cylindrospermopsis, Geitlerinema, Glaucospira, Limnothrix, Pannus, Phormidium, Planktolyngbya, Planktothrix, Sphaerocavum e Synechocystis, com uma espécie cada. Treze espécies foram registradas na literatura como potencialmente tóxicas: Cylindrospermopsis raciborskii, Dolichospermum circinalis, D. crassum, $D$. flos-aquae, D. planctonicum, D. spiroides, Oscillatoria limosa, Planktothrix agardhii, Microcystis aeruginosa, M. protocystis, $M$. wesenbergii, Radiocytis fernandoi $\mathrm{e}$ Geitlerinema amphibium.

Chave para as cianobactérias encontradas no lago Jaó

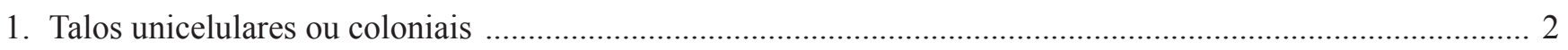

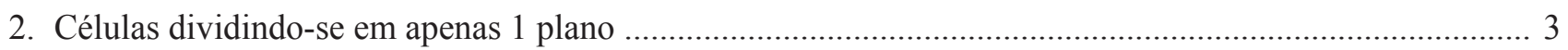

3. Talos unicelulares, vivendo no interior da mucilagem de colônias de outras cianobactérias

Synechocystis endobiotica

3. Talos coloniais, vivendo livremente na coluna d'água 4

4. Células cilíndricas com no máximo $1 \mu \mathrm{m}$ de diâmetro, enfileiradas formando um tubo Bacularia gracilis

4. Células esféricas a alongadas com diâmetro sempre maior que $1 \mu \mathrm{m}$, organizadas radialmente na colônia 5

5. Células com aerótopos Radiocystis fernandoi

5. Células sem aerótopos Radiocystis cf. geminata

2. Células dividindo-se em 2 ou mais planos

6. Células dividindo-se em 2 planos 6

7. Colônias ocas .

8. Células com aerótopos Sphaerocavum brasiliense

8. Células sem aerótopos 9

9. Células com até $2 \mu \mathrm{m}$ de diâmetro Pannus cf. spumosum

9. Células com mais de $4 \mu \mathrm{m}$ de diâmetro Coelosphaerium limnicolum

7. Colônias maciças 10 10. Diâmetro das células com até $2 \mu \mathrm{m}$ 11 
11. Células menores que $1,3 \mu \mathrm{m}$ de diâmetro organizadas em colônias esféricas a levemente elipsoidais Aphanocapsa delicatissima

11. Células maiores que $1,3 \mu \mathrm{m}$ de diâmetro, frouxamente organizadas em colônias elipsoidais a irregulares (nunca esféricas) Aphanocapsa elachista

10. Diâmetro das células sempre maior que $2 \mu \mathrm{m}$ 12

12. Colônias com células frouxamente agregadas Aphanocapsa koordesii

12. Colônias com células densamente agregadas Aphanocapsa annulata

6. Células dividindo-se em 3 planos 13

13. Colônias com mucilagem estreita e conspícua Microscytis wesenbergii

13. Colônias com mucilagem ampla e inconspícua 14

14. Colônias clatradas, células densamente agregadas e sem envelope mucilaginoso individual

Microcystis aeruginosa

14. Colônias não clatradas, células frouxamente organizadas e com presença de envelope mucilaginoso individual Microcystis protocystis

1. Talos filamentosos 15

15. Tricomas vivendo no interior da mucilagem de outras cianobactérias e algas .... Pseudanabaena mucicola

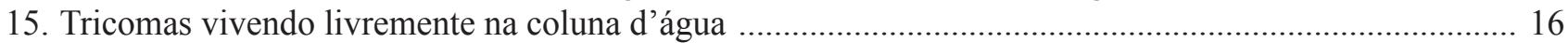

16. Tricomas homocitados 17

17. Tricomas regularmente espiralados Glaucospira sp.

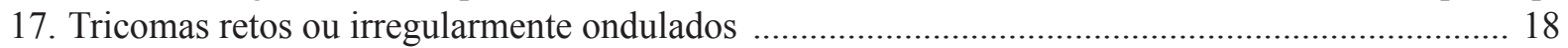

18. Tricomas com células isodiamétricas ou mais longas que largas ....................................... 19

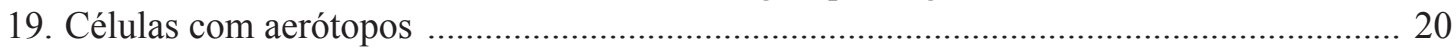

20. Aerótopos localizados apenas nos pólos das células .............. Pseudanabaena galeata

20. Aerótopos dispersos em toda a célula .................................................................. 21

21. Tricomas com até $3,5 \mu \mathrm{m}$ de largura ................................... Limnothrix guttulata

21. Tricomas acima de $4 \mu \mathrm{m}$ de largura ................................. Planktothrix agardhii

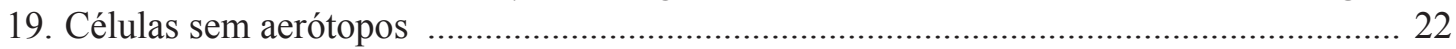

22. Tricomas atenuados para os ápices

Phormidium formosum

22. Tricomas não atenuados para os ápices 23

23. Tricomas com bainha mucilaginosa Planktolyngbya limnetica

23. Tricomas sem bainha mucilaginosa 24

24. Células com septos constritos

24. Células com septos não constritos

Pseudanabaena catenata Geitlerinema amphibium

18. Tricomas com células mais largas que longas

25. Células com aerótopos

25. Células sem aerótopos

Oscillatoria perornata Oscillatoria limosa

16. Tricomas heterocitados 26

26. Tricomas atenuados em direção aos ápices; heterócito terminal ... Cylindrospermopsis raciborskii

26. Tricomas não atenuados em direção aos ápices; heterócito intercalar

27. Tricomas retos 27

27. Tricomas espiralados Dolichospermum plactonicum

28. Filamentos com bainha mucilaginosa com cerca de 1,5 vez o diâmetro da célula vegetativa ou menor 28

29. Tricomas com diâmetro da espira inferior a $70 \mu \mathrm{m}$ Dolichospermum flos-aquae

29. Tricomas com diâmetro da espira superior a $70 \mu \mathrm{m}$ Dolichospermum circinalis

28. Filamentos com bainha mucilaginosa sempre maior que 1,5 vez o diâmetro da célula vegetativa 30

30. Tricomas regularmente espiralados, espiras com diâmetro sempre maior que $35 \mu \mathrm{m}$ Dolichospermum crassum

30. Tricomas regular até irregularmente espiralado, espiras com diâmetro menor que $35 \mu \mathrm{m}$ Dolichospermum spiroides 


\section{SYNECHOCOCCOPHYCIDAE}

\section{MERISMOPEDIACEAE}

Aphanocaspsa Nägeli, 1849.

Aphanocapsa annulata G. McGregor, Nova Hedwigia 84: 299. 2007.

Figuras 1-3

Colônias jovens esféricas a elipsoidais, tornando-se irregularmente alongadas, ovais ou distintamente aneladas quando adultas, 55-110 $\mu$ m compr., 18-100 $\mu \mathrm{m}$ larg., células densamente arranjadas. Mucilagem hialina, difluente, homogênea, margem ampla, 10,6-26,7 $\mu$ m espes. Células esféricas, 2,7-3,2 $\mu \mathrm{m}$ diâm., conteúdo homogêneo.

Material examinado: BRASIL. GoIÁs: Goiânia, lago Jaó, 19-IX-08, I.S. Nogueira 1214 (UFG40988), 19-IX-08, I.S. Nogueira 1215 (UFG40989), 11-XI-09, I.S. Nogueira \& W.A. Gama Jr. 1222 (UFG42230), 11-XI-09, I.S. Nogueira \& W.A. Gama Jr. 1223 (UFG42231), 11-XI-09, I.S. Nogueira \& W.A. Gama Jr. 1224 (UFG42232); 11-XI-09, I.S. Nogueira \& W.A. Gama Jr. 1225 (UFG42233).

Essa espécie é bem reconhecida quando observada no estágio de anel (figura 3) e foi originalmente descrita para a Austrália (McGregor et al. 2007). No primeiro estágio, a forma esférica de $A$. annulata (figura 1) se assemelha a $A$. incerta. Porém, a ampla mucilagem de A. annulata é diacrítica na distinção dessas espécies.

Distribuição geográfica no Estado de Goiás: primeira citação do táxon.

Aphanocapsa delicatissima W. West \& G.S. West, J. Linn. Soc. Bot. 40: 431. 1912.

Figura 4

Colônias esféricas, 23-65 $\mu \mathrm{m}$ diâm., células dispostas frouxa e irregularmente. Mucilagem hialina, difluente, homogênea, margem estreita, adjacente às células da periferia da colônia. Células esféricas, 0,8-1,2 $\mu \mathrm{m}$ diâm., conteúdo homogêneo.

Aphanocapsa delicatissima possui registros principalmente para a região temperada. Porém, Komárek \& Anagnostidis (1998) mencionam que essa espécie provavelmente é cosmopolita e Sant'Anna et al. (2004) registraram-na para o reservatório de Paraibuna (SP).

Material examinado: BRASIL. GoIÁs: Goiânia, lago Jaó, 19-IX-08, I.S. Nogueira 1214 (UFG40988), 19-IX-08, I.S. Nogueira 1215 (UFG40989), 28-V-08, I.S. Nogueira 1216 (UFG40990), 01-IX-04, I.S. Nogueira 1219 (UFG40993), 11-XI-09, I.S. Nogueira \& W.A. Gama Jr. 1222 (UFG42230), 11-XI-09, I.S. Nogueira \& W.A. Gama Jr. 1224 (UFG42232).
Distribuição geográfica no Estado de Goiás: primeira citação do táxon.

Aphanocapsa elachista W. West \& G.S. West, Journ. Linn. Soc. 30: 276. 1894.

Figura 5

Colônias alongadas, 26,6-90,2 $\mu \mathrm{m}$ compr., 36$100 \mu \mathrm{m}$ larg., células dispostas frouxa e irregularmente. Mucilagem hialina, difluente, homogênea, margem estreita, adjacente às células da periferia da colônia. Células esféricas, 1,3-2,5 $\mu$ m diâm., conteúdo homogêneo.

Aphanocapsa elachista (células com diâmetro acima de $1,3 \mu \mathrm{m}$ ) e $A$. delicatissima (no máximo $1,2 \mu \mathrm{m}$ ) se diferenciaram basicamente em relação ao tamanho da célula e à forma da colônia.

Material examinado: BRASIL. GoIÁs: Goiânia, lago Jaó, 19-IX-08, I.S. Nogueira 1214 (UFG40988), 19-IX-08, I.S. Nogueira 1215 (UFG40989), 28-V-08, I.S. Nogueira 1216 (UFG40990), 01-IX-04, I.S. Nogueira 1219 (UFG40993).

Distribuição geográfica no Estado de Goiás: primeira citação do táxon.

Aphanocapsa koordersii Strøm, Nyt Mag. Naturv. 61: 128. 1923.

Figura 6

Colônias subesféricas ou irregulares, 42-53 $\mu \mathrm{m}$ diâm., células frouxa e irregularmente dispostas, às vezes em grupos de até quatro, subcolônias frequentemente presentes. Mucilagem hialina, homogênea, difluente, margem ampla, 9-14 $\mu \mathrm{m}$ espes. Células esféricas ou subesféricas, 2,3-3 $\mu \mathrm{m}$ diâm., com um grânulo no centro.

Esta espécie é citada por Komárek \& Cronberg (2001) como ocorrente em regiões tropicais. Estes mesmos autores indicaram o registro de uma estrutura central na célula, a qual denominaram provisoriamente de aerótopo. Uma estrutura semelhante foi observada nos espécimes do lago Jaó, a qual foi denominada como grânulo até que se defina ultra-estruturalmente do que se trata, pois a presença de aerótopo não é descrita na diagnose de Aphanocapsa.

Material examinado: BRASIL. GoIÁs: Goiânia, lago Jaó, 19-IX-08, I.S. Nogueira 1214 (UFG40988), 19IX-08, I.S. Nogueira 1215 (UFG40989), 11-IX-09, I.S. Nogueira \& W.A. Gama Jr. 1223 (UFG42231), 11-XI-09, I.S. Nogueira \& W.A. Gama Jr. 1224 (UFG42232).

Distribuição geográfica no Estado de Goiás: primeira citação do táxon. 

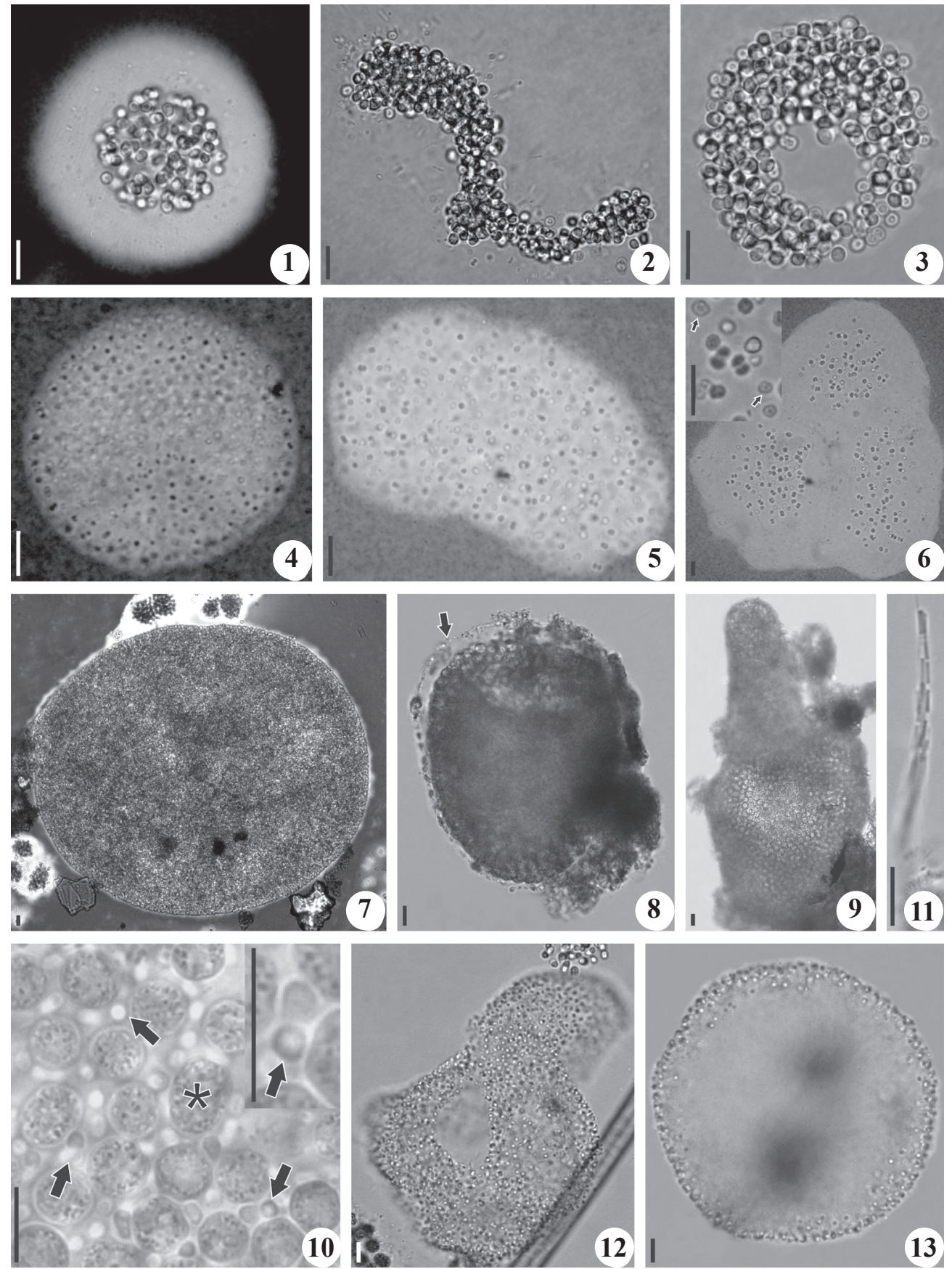

Figuras 1-13. 1-3. Aphanocapsa annulata. 1. Estágio inicial de desenvolvimento, colônia esférica. 2. Estágio intermediário de desenvolvimento, colônia alongada. 3. Estágio final de desenvolvimento, colônia anelada. 4. Aphanocapsa delicatissima. 5. Aphanocapsa elachista. 6. Aphanocapsa koordersii. Colônia com subcolônias, células com grânulo solitário (setas). 7-9. Coelosphaerium limnocolum. 7. Colônia esférica. 8. Aspecto oco da colônia, envoltório mucilaginoso (seta). 9. Colônia alongada. 10. Células de Coelosphaerium limnocolum (asterisco) e Synechocystis endobiotica (setas). 11. Bacularia gracilis. 12-13. Pannus cf. spumosus. 12. Colônia lobada. 13. Colônia esférica, oca. Barra $=10 \mu \mathrm{m}$

Figures 1-13. 1-3. Aphanocapsa annulata. 1. Initial stage of development, spherical colony. 2. Intermediary stage of development, elongated colony. 3. Final stage of development, looped colony. 4. Aphanocapsa delicatissima. 5. Aphanocapsa elachista. 6. Aphanocapsa koordersii. Colony with subcolonies, cells with solitary granule (arrows). 7-9. Coelosphaerium limnocolum. Spherical colony. 8. Hollow aspect of colony, mucilaginous envolope (arrow). 9. Elongated colony. 10. Cells of Coelosphaerium limnocolum (asterisk) and Synechocystis endobiotica (arrows). 11. Bacularia gracilis. 12-13. Pannus cf. spumosus. 12. Lobed colony. 13. Spherical hollow colony. Bar $=10 \mu \mathrm{m}$, 
Coelosphaerium Nägeli, 1849.

Coelosphaerium limnicolum Lund, J. Bot. (London) 80: 66. 1942.

Figuras 7-9

Colônias ocas, esféricas, 141-716 $\mu \mathrm{m}$ diâm., até alongadas, 129-291,3 $\mu \mathrm{m}$ compr., 117,1-145 $\mu \mathrm{m}$ larg., tornando-se irregulares, com subcolônias, células dispostas em uma (raramente duas) camadas na periferia. Mucilagem hialina, homogênea, difluente, margem ampla, 5-19 $\mu \mathrm{m}$ espes. Células esféricas a oblongas, 4,36,3 $\mu \mathrm{m}$ diâm., com grânulos dispersos no citoplasma, sem aerótopos.

Material examinado: BRASIL. GoiÁs: Goiânia, lago Jaó, 11-XI-09, I.S. Nogueira \& W.A. Gama Jr. 1222 (UFG42230).

Distribuição geográfica no Estado de Goiás: primeira citação do táxon.

Synechocystis Sauvageau, 1892.

Synechocystis endobiotica (Elenkin \& Hollerbach) Elenkin \& Hollerbarch in Elenkin, Monographia Algarum Cyanophycearum Aquidulcium et Terrestrium in Finibus URSS Inventarum. Fasc. 1. Akad. Nauk SSSR. 1938.

Figura 10

Células solitárias ou em pequenos grupos, esféricas a alongadas quando em divisão, vivendo dentro de colônias de outras cianobactérias, 1,6-2,0 $\mu \mathrm{m}$ diâm.

Esta espécie foi encontrada associada a Coelosphaerium limnicolum, presente tanto no interior como na superfície das colônias.

Material examinado: BRASIL. GoIÁs: Goiânia, lago Jaó, 11-XI-09, I.S. Nogueira \& W.A. Gama Jr. 1222 (UFG42230).

Distribuição geográfica para o Estado de Goiás: primeira citação do táxon.

\section{SYNECHOCOCCACEAE}

Bacularia Borzì, 1905.

Bacularia gracilis Komárek, Folia Geobot. et Phytotax. 30: 86. 1995.

Figura 11

Colônias alongadas, tubulares, afilando-se para os ápices, 102-146 $\mu \mathrm{m}$ compr., 20-33 $\mu \mathrm{m}$ larg., células dispostas em fileiras, com o maior eixo paralelo à margem da colônia, mas não formando pseudofilamentos. Mucilagem hialina, homogênea, conspícua, margem estreita. Células cilíndricas, 3,8-4,2 $\mu$ m compr., 0,5-0,7 $\mu \mathrm{m}$ larg., conteúdo homogêneo.
Material examinado: BRASIL. GoIÁs: Goiânia, lago Jaó, 11-XI-09, I.S. Nogueira \& W.A. Gama Jr. 1222 (UFG42230).

Distribuição geográfica no Estado de Goiás: primeira citação do táxon.

Pannus Hickel, 1991.

Pannus cf. spumosus Hickel, Arch. Hydrobiol. Suppl. 92 (Algolog. Stud. 64): 101. 1991.

Figuras 12-13

Colônias esféricas a irregulares, 80-251 $\mu \mathrm{m}$ compr., 83-223 $\mu \mathrm{m}$ larg., ocas, tardiamente lobadas e clatradas, células arranjadas densamente. Mucilagem hialina, difluente e estreita. Células esféricas, com um grânulo, 1,3-1,6 $\mu \mathrm{m}$ diâm., sem aerótopos.

As colônias observadas neste estudo possuem dimensões maiores do que foram descritas originalmente $\mathrm{e}$ a presença de grânulos também não é citada na descrição original da espécie. Todavia, a forma das colônias, esféricas quando jovens e irregulares quando velhas, e o fato de serem ocas e lobadas são características de Pannus. Pela forma da colônia, diâmetro celular e ausência de aerótopos nos indivíduos analisados a espécie encontrada na literatura mais próxima ao observado é $P$. spumosus. Porém esta espécie é de ocorrência para a região temperada e as células possuem envoltório mucilaginoso individual, o que não foi observado na população encontrada.

Material examinado: BRASIL. GoIÁs: Goiânia, lago Jaó, 11-XI-09, I.S. Nogueira \& W.A. Gama Jr. 1222 (UFG42230), 11-XI-09, I.S. Nogueira \& W.A. Gama Jr. 1223 (UFG42231), 11-XI-09, I.S. Nogueira \& W.A. Gama Jr. 1225 (UFG42233).

Distribuição geográfica no Estado de Goiás: primeira citação do táxon.

\section{PSEUDANABAENACEAE}

Geitlerinema (Anagnostidis \& Komárek) Anagnostidis, 1989.

Geitlerinema amphibium (Agardh ex Gomont) Anagnostidis, Pl. Syst. \& Evol. 164(1/4): 33. 1989.

Figura 14-15

Tricomas móveis, retos, raramente curvos, septos não constritos, translúcidos. Ápices não atenuados ou levemente atenuados, não captados. Células mais longas que largas, 4,0-8,4 $\mu \mathrm{m}$ compr., 1,7-2,6 $\mu \mathrm{m}$ larg. com um grânulo disposto em cada lado dos septos. Célula apical cilíndrico-arredondada, raramente achatada.

Duas populações semelhantes a G. amphibium e $G$. unigranulatum foram identificadas neste estudo. Porém, Bittencourt-Oliveira et al. (2009), baseados em estudos 
morfométricos, ultra-estruturais e moleculares, sugeriram que G. unigranulatum fosse considerada sinônimo de G. amphibium. Por esse motivo, considerou-se as duas populações encontradas como G. amphibium, uma vez que este é o nome mais antigo e ainda não ocorreu a sinonimização de G. unigranulatum.

Material examinado: BRASIL. GoiÁs: Goiânia, lago Jaó, 19-IX-08, I.S. Nogueira 1214 (UFG40988), 11-XI-09, I.S. Nogueira \& W.A. Gama Jr. 1222 (UFG42230), 11-XI-09, I.S. Nogueira \& W.A. Gama Jr. 1223 (UFG42231).

Distribuição geográfica no Estado de Goiás: Anápolis: Ribeirão João Leite (Nogueira et al. 2002), Goiânia: represa Samambaia (Nogueira et al. 2002), Bosque dos Buritis (Nogueira et al. 2008), Jardim Botânico (Nogueira et al. 2008), lago do Parque Vaca Brava (Nogueira et al. 2008), lago das Rosas (Nogueira et al. 2008).

Limnothrix Meffert, 1988.

Limnothrix guttulata (Goor) Umezaki \& M. Watanabe, Jap. J. Phycol. 42: 207. 1994.

Figura 16

Tricomas móveis, ondulados, septos não constritos, inconspícuos. Ápices não atenuados. Células mais ou menos isodiamétricas até duas vezes mais longas que largas, 5,2-7,2 $\mu \mathrm{m}$ compr., 2,4-3,5 $\mu \mathrm{m}$ de larg., 2-6 aerótopos dispersos irregularmente pelo conteúdo celular. Célula apical cilíndrico-arredondada.

Os tricomas dessa espécie não foram encontrados isolados, mas sempre ocorrendo emaranhados com outras cianobactérias, principalmente Phormidium e Oscillatoria.

Material examinado: BRASIL. GoIÁs: Goiânia, lago Jaó, 11-XI-09, I.S. Nogueira \& W.A. Gama Jr. 1222 (UFG42230), 11-XI-09, I.S. Nogueira \& W.A. Gama Jr. 1223 (UFG42231).

Distribuição geográfica no Estado de Goiás: primeira citação do táxon.

Planktolyngbya Anagnostidis \& Komárek, 1988.

Planktolyngbya limnetica (Lemmermann) KomárkováLegnerová \& Cronberg, Arch. Hydrobiol. Suppl. 95 (Algolog. Stud. 67): 23. 1992.

Figuras 17-18

Tricomas imóveis, retos ou levemente curvados, septos não constritos. Ápices não atenuados. Bainha fina, incolor, conspícua. Células cilíndricas, 1,92,6 $\mu \mathrm{m}$ compr., 1,5-2,0 $\mu \mathrm{m}$ larg. aerótopos ausentes, às vezes com grânulos solitários.
Material examinado: BRASIL. GoIÁs: Goiânia, lago Jaó, 11-XI-09, I.S. Nogueira \& W.A. Gama Jr. 1222 (UFG42230), 11-XI-09, I.S. Nogueira \& W.A. Gama Jr. 1223 (UFG42231).

Distribuição geográfica no Estado de Goiás: Goiânia: Bosque dos Buritis (Nogueira et al. 2008); Jardim Botânico (Nogueira et al. 2002, Nogueira et al. 2008), lago do Parque Vaca Brava (Nogueira et al. 2002, Nogueira et al. 2008; Nardini \& Nogueira 2008), lago das Rosas (Nogueira et al. 2008), represa Samambaia (Nogueira et al. 2002).

Pseudanabaena Lauterborn, 1915.

Pseudanabaena catenata Lauterborn, Verhandlungen des Naturhistorisch-Medizinischen Vereins zu Heidelberg, ser. 2, 13: 437. 1915.

Figura 19

Tricomas móveis, flexuosos, septos constritos, translúcidos. Ápices não atenuados. Células cilíndricas, 4,5-6,0 $\mu \mathrm{m}$ compr., 1,6-2,3 $\mu \mathrm{m}$ larg., conteúdo celular homogêneo, claramente distinguível em cromato e centroplasma. Célula apical cilíndrico-arredondada ou levemente cônico-truncada.

Os principais caracteres utilizados para diferenciar esta espécie de $P$. galeata foram a ausência de grânulos e de aerótopos nos septos, além do menor comprimento das células.

Material examinado: BRASIL. Goís: Goiânia, lago Jaó, 11-XI-09, I.S. Nogueira \& W.A. Gama Jr. 1222 (UFG42230), 11-XI-09, I.S. Nogueira \& W.A. Gama Jr. 1223 (UFG42231).

Distribuição geográfica no Estado de Goiás: primeira citação do táxon.

Pseudanabaena galeata Böcher, K. Danske Vid. Selsk. Biol. Medd. 21: 13. 1949.

Figura 20

Tricomas móveis, retos ou curvados, septos constritos. Ápices não atenuados. Células cilíndricas, 4,59,0 $\mu \mathrm{m}$ compr., 1,8-2,0 $\mu \mathrm{m}$ larg., dois (frequentemente pequenos) aerótopos polares, conteúdo granular, distinguível em cromato e centroplasma. Célula apical cilíndrico-arredondada, raramente cônica.

Material examinado: BRASIL. GoIÁs: Goiânia, lago Jaó, 11-XI-09, I.S. Nogueira \& W.A. Gama Jr. 1222 (UFG42230), 11-XI-09, I.S. Nogueira \& W.A. Gama Jr. 1223 (UFG42231).

Distribuição geográfica no Estado de Goiás: primeira citação do táxon. 
Pseudanabaena mucicola (Naumann \& Huber-Pestalozzi) Schwabe, Arch. Hydrobiol. Suppl. 71: 151. 1964.

Figuras 21-22

Tricomas imóveis, retos, curtos (três a seis células), ocorrendo dentro da mucilagem de outras cianobactérias e algas, septos constritos. Ápices não ou levemente atenuados. Células cilíndricas, sempre mais longas que largas ou raramente quadráticas, 1,82,6 $\mu \mathrm{m}$ diâm., conteúdo celular homogêneo, septos não granulosos, sem aerótopos. Célula apical cônica e sem espessamento.

P. mucicola foi encontrada habitando a mucilagem de Microcystis aeruginosa (Kütz.) Kütz., Radiocystis cf. geminata Skuja e também de Kirchneriella dianae (Bohlin) Comas.

Material examinado: BRASIL. GoIÁs: Goiânia, lago Jaó, 19-IX-08, I.S. Nogueira 1214 (UFG40988), 19-IX-08, I.S. Nogueira 1215 (UFG40989), 11-XI-09, I.S. Nogueira \& W.A. Gama Jr. 1222 (UFG42230), 11-XI-09, I.S. Nogueira \& W.A. Gama Jr. 1223 (UFG42231), 11-XI-09, I.S. Nogueira \& W.A. Gama Jr. 1224 (UFG42232), 11-XI-09, I.S. Nogueira \& W.A. Gama Jr. 1225 (UFG42233).

Distribuição geográfica no Estado de Goiás: primeira citação do táxon.

\section{OSCILLATORIOPHYCIDAE}

\section{MICROCYSTACEAE}

Microcystis Kützing ex Lemmermann, 1907.

Microcystis aeruginosa (Kützing) Kützing, Tab. Phyc. 1: 6.1846.

Figuras 23-24

Colônias arredondadas ou alongadas, quando velhas clatradas, 31,5-330,0 $\mu \mathrm{m}$ diâm., células irregularmente dispostas em diferentes planos, próximas umas das outras, às vezes com subcolônias presentes. Mucilagem inconspícua, hialina, difluente, margem ampla, até $18 \mu \mathrm{m}$ espes. Células esféricas, 5,0-7,5 $\mu \mathrm{m}$ diâm., desprovidas de envelope mucilaginoso individual, aerótopos presentes.

Material examinado: BRASIL. GoiÁs: Goiânia, lago Jaó, 24-IV-07, I.S. Nogueira 1213 (UFG40987), 19-IX-08, I.S. Nogueira 1214 (UFG40988), 28-V-08, I.S. Nogueira 1216 (UFG40990), 24-IV-07, I.S. Nogueira 1217 (UFG40991), 07-IV-07, I.S. Nogueira 1218 (UFG40992), 25-IV-07, I.S. Nogueira 1220 (UFG40994), 15-IV-06, I.S. Nogueira 1221 (UFG40995), 11-XI-09, I.S. Nogueira \& W.A. Gama Jr. 1223 (UFG42231), 11-XI-09, I.S. Nogueira \& W.A. Gama Jr. 1224
(UFG42232), 11-XI-09, I.S. Nogueira \& W.A. Gama Jr. 1225 (UFG42233).

Distribuição geográfica no Estado de Goiás: Caldas Novas: reservatório de Corumbá (Silva et al. 2001); Goianápolis: Ribeirão João Leite (Nogueira et al. 2002); Goiânia: Bosque dos Buritis (Nascimento-Bessa \& Santos 1995; Nogueira et al. 2008); Jardim Botânico (Nogueira et al. 2008), lago do Parque Vaca Brava (Nogueira et al. 2002, Nogueira et al. 2008; Nardini \& Nogueira 2008), lago das Rosas (Nogueira et al. 2008); Ribeirão João Leite (Saneago 1996, Nogueira et al. 2002); Inhumas: Lagoa de estabilização (Nogueira et al. 2002); Luiz Alves: lagoa Brito (Nogueira et al. 2002); Teresópolis: Ribeirão João Leite (Nogueira et al. 2002); sem indicação de localidade: Goiás (Campos et al. 1990).

Microcystis protocystis Crow, New Phytol, 22(2): 62. 1923.

Figura 25

Colônias arredondadas a alongadas, 96,2168,4 $\mu$ m compr., células frouxa e irregularmente dispostas. Mucilagem hialina, difluente, bordas irregulares, marcadas por reentrâncias. Células esféricas, levemente alongadas antes da divisão, 3,7-7,8 $\mu \mathrm{m}$ diâm., envelopes mucilaginosos individuais presentes, aerótopos presentes.

Komárek \& Anagnostidis (1998) e Komárek \& Komárková (2002) indicaram que $M$. protocystis é uma espécie tropical. Esta espécie pode ser distinguida de $M$. aeruginosa por apresentar células distribuídas espaçadamente em toda a mucilagem. Outra característica diacrítica entre esses táxons é a presença de um envelope mucilaginoso em cada célula de $M$. protocystis, às vezes de difícil visualização, conforme registrado em Komárek \& Komárková (2002). A presença de células maiores, bainha mais ampla e com presença de reentrâncias na mucilagem de $M$. protocystis tornam possível distinguir esta espécie de $M$. panniformis.

Material examinado: BRASIL. GoIÁs: Goiânia, lago Jaó, 24-IV-07, I.S. Nogueira 1213 (UFG40987), 19-IX-08, I.S. Nogueira 1214 (UFG40988), 24-IV07, I.S. Nogueira 1217 (UFG40991), 07-IV-07, I.S. Nogueira 1218 (UFG40992), 25-IV-07, I.S. Nogueira 1220 (UFG40994), 15-IV-06, I.S. Nogueira 1221 (UFG40995), 11-XI-09, I.S. Nogueira \& W.A. Gama Jr. 1224 (UFG42232), 11-XI-09, I.S. Nogueira \& W.A. Gama Jr. 1225 (UFG42233).

Distribuição geográfica no Estado de Goiás: Goiânia: lago das Rosas (Nogueira et al. 2008). 
Microcystis wesenbergii (Komárek) Komárek in Kondrateva 1968, Vizn. prisnov. vodor. URSR 1/2: 524. 1968.

Figura 26

Colônias esféricas quando jovens, alongadas, lobadas, irregulares clatradas na fase adulta, 52,5190,0 $\mu$ m compr., células distribuídas irregularmente, subcolônias presentes. Mucilagem hialina, homogênea, conspícua, contorno espesso, refringente, firme. Células esféricas, levemente alongadas antes da divisão, 5,27,8 $\mu \mathrm{m}$ diâm., aerótopos presentes.

Material examinado: BRASIL. GoIÁs: Goiânia, lago Jaó, 19-IX-08, I.S. Nogueira 1214 (UFG40988), 19-IX-08, I.S. Nogueira 1215 (UFG40989), 11-XI-09, I.S. Nogueira \& W.A. Gama Jr. 1224 (UFG42232).

Distribuição geográfica no Estado de Goiás: Goiânia: lago das Rosas, lago do Bosque dos Buritis e lago do parque Vaca Brava (Nogueira et al. 2008; Nardini \& Nogueira 2008).

Radiocystis Skuja, 1948.

Radiocystis fernandoi Komárek \& KomárkováLegnerová, Preslia 65: 355. 1993.

Figura 27

Colônias arredondadas a elipsoidais, 37$90 \mu \mathrm{m}$ diâm., células dispostas radialmente. Mucilagem hialina, homogênea, difluente, margem ampla, 5-11 $\mu \mathrm{m}$ espes. Células esféricas a levemente alongadas, 2,3-3,7 $\mu \mathrm{m}$ diâm., aerótopos presentes.

Material examinado: BRASIL. GoIÁs: Goiânia, lago Jaó, 24-IV-07, I.S. Nogueira 1213 (UFG40987), 19-IX-08, I.S. Nogueira 1214 (UFG40988), 28-V-08, I.S. Nogueira 1216 (UFG40990), 24-IV-07, I.S. Nogueira 1217 (UFG40991), 07-IV-07, I.S. Nogueira 1218 (UFG40992), 01-IX-04, I.S. Nogueira 1219 (UFG40993), 25-IV-07, I.S. Nogueira 1220 (UFG40994), 15-IV-06, I.S. Nogueira 1221 (UFG40995), 11-XI-09, I.S. Nogueira \& W.A. Gama Jr. 1223 (UFG42231), 11-XI-09, I.S. Nogueira \& W.A. Gama Jr. 1224 (UFG42232), 11-XI-09, I.S. Nogueira \& W.A. Gama Jr. 1225 (UFG42233).

Distribuição geográfica no Estado de Goiás: Goiânia: lago do Jardim Botânico, lago do parque Vaca Brava, lago do Bosque dos Buritis e lago das Rosas (Nogueira et al. 2002; Nogueira et al. 2008; Nardini \& Nogueira 2008).

Radiocystis cf. geminata Skuja, Symb. Bot. Upsal. 9(3): 44. 1948.

Figuras 28-29

Colônias subesféricas, levemente alongadas 28,553,0 $\mu \mathrm{m}$ compr., 24,5-38,5 $\mu \mathrm{m}$ de larg., células dispostas radialmente, subcolônias presentes. Mucilagem hialina, homogênea, difluente, margem ampla, 17,5-20,5 $\mu \mathrm{m}$ espes. Células esféricas a levemente alongadas, 4,1-

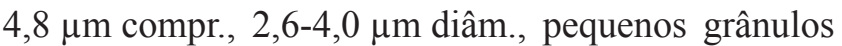
presentes, sem aerótopos.

Os espécimes encontrados possuíam disposição das células em linhas partindo do centro, o que é típico de Radiocystis e foi usado como caráter discriminatório em relação às espécies de Aphanocapsa. Porém, a ausência total de aerótopos, a ampla mucilagem observada em alguns indivíduos e a ocorrência ter sido registrada para ambiente tropical, são características que impedem afirmar que a população encontrada realmente seja de $R$. geminata.

Material examinado: BRASIL. GoiÁs: Goiânia, lago Jaó, 11-XI-09, I.S. Nogueira \& W.A. Gama Jr. 1223 (UFG42231), 11-XI-09, I.S. Nogueira \& W.A. Gama Jr. 1224 (UFG42232), 11-XI-09, I.S. Nogueira \& W.A. Gama Jr. 1225 (UFG42233).

Distribuição geográfica no Estado de Goiás: primeira citação do táxon.

Sphaerocavum Azevedo \& Sant'Anna, 2003. Sphaerocavum brasiliense Azevedo \& Sant'Anna, Arch. Hydrobiol. Suppl. 148 (Algolog. Stud. 109): 79. 2003. Figuras 30-31

Colônias esféricas, ocas, quando jovens oblongas a alongadas, irregulares na fase adulta, 77,5-200,0 $\mu \mathrm{m}$ compr., $\quad 85-137 \mu \mathrm{m}$ larg., células frouxamente distribuídas, às vezes enfileiradas na periferia da colônia. Mucilagem hialina, homogênea, difluente, adjacente às células da periferia da colônia. Células esféricas, oblongas antes da divisão, 3,2-5,0 $\mu \mathrm{m}$ diâm., aerótopos presentes.

Populações de $S$. brasiliense podem ser facilmente confundidas com as de Microcystis, principalmente com as de M. panniformis, pois ambas as espécies apresentam mucilagem estreita, células esféricas com aerótopos e conteúdo marrom-esverdeado. Porém, Sphaerocavum é um gênero que se caracteriza pelas colônias sempre ocas, diferentemente de Microcystis, que possui colônias com células arranjadas na periferia e interior.

Material examinado: BRASIL. GoIÁs: Goiânia, lago Jaó, 19-IX-08, I.S. Nogueira 1214 (UFG40988), 11-XI-09, I.S. Nogueira \& W.A. Gama Jr. 1223 (UFG42231), 11-XI-09, I.S. Nogueira \& W.A. Gama Jr. 1224 (UFG42232), 11-XI-09, I.S. Nogueira \& W.A. Gama Jr. 1225 (UFG42233).

Distribuição geográfica no Estado de Goiás: primeira citação do táxon. 

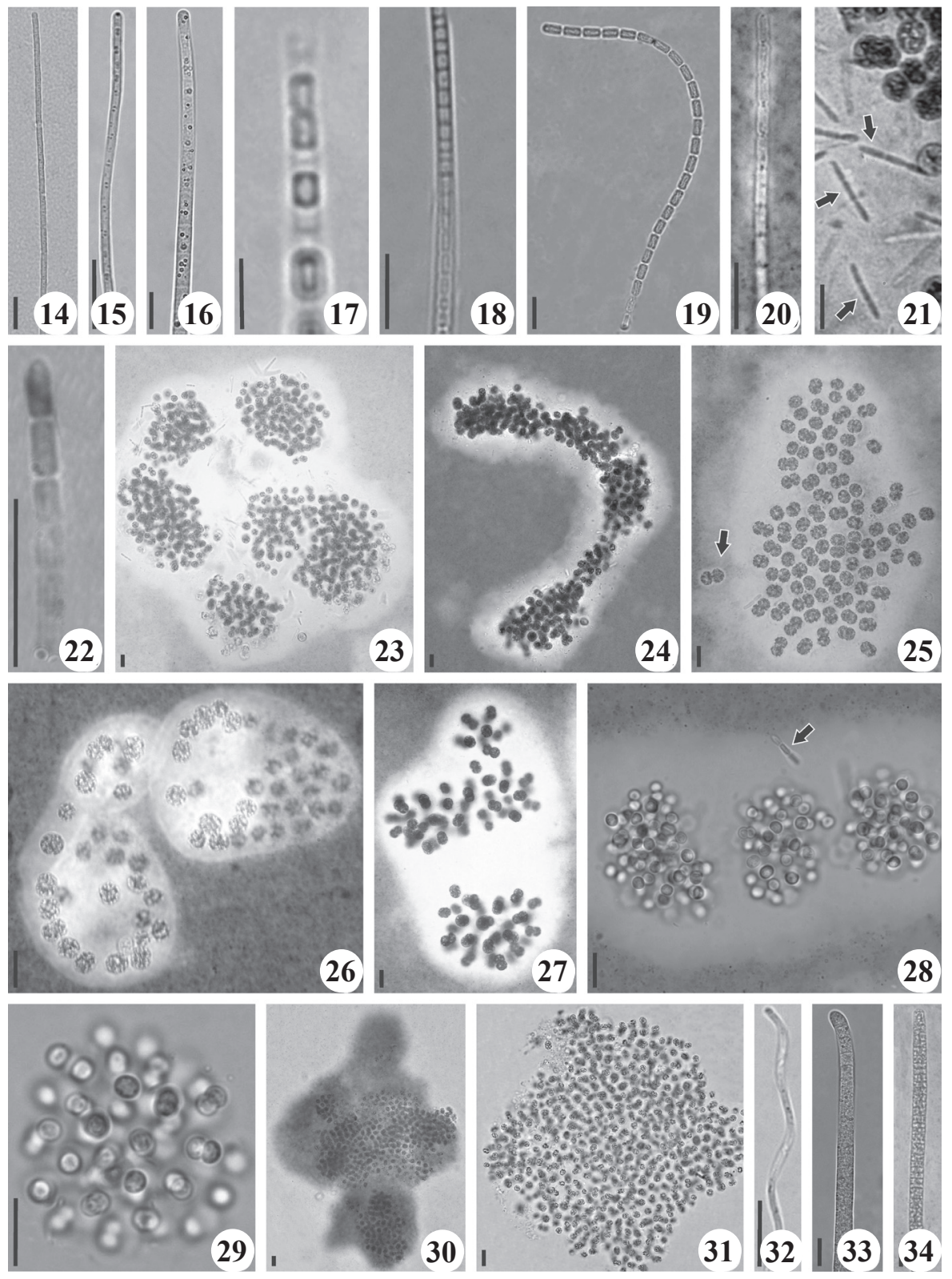

Figuras 14-34. 14-15. Geitlerinema amphibium. 14. Tricoma reto, grânulos dispersos no citoplasma. 15. Tricoma com um grânulo em cada lado do septo. 16. Limnothrix gutullata. 17-18. Planktolyngbya limnetica. 17. Células apicais do tricoma. 18. Células intermediárias do tricoma. 19. Pseudanabaena catenata. 20. Pseudanabaena galeata. 21. Células de Microcystis aeruginosa e tricomas de Pseudanabaena mucicola (setas). 22. Pseudanabaena mucicola. 23-24. Microcystis aeruginosa. 23. Colônias com subcolônias. 24. Colônia alongada. 25. Microcystis protocystis, células com envoltório mucilaginoso individual (seta). 26. Microcystis wesenbergii. 27. Radiocystis fernandoi. 28-29. Radiocystis cf. geminata. 28. Colônia com subcolônias, tricoma de Pseudanabaena mucicola (seta). 29. Organização radial das células. 30-31. Sphaerocavum brasiliense. 32. Glaucospira sp. 33. Phormidium formosum. 34. Planktothrix agardhii. Barra $=10 \mu \mathrm{m}$

Figures 14-34. 14-15. Geitlerinema amphibium. 14. Straight trichome, granules scattered in the cytoplasm. 15. Trichome with one granule in each side of cross-wall. 16. Limnothrix gutullata. 17-18. Planktolyngbya limnetica. 17. Apical cells of trichome. 18. Intermediary cells of trichome. 19. Pseudanabaena catenata. 20. Pseudanabaena galeata. 21. Cells of Microcystis aeruginosa and trichomes of Pseudanabaena mucicola (arrows). 22. Pseudanabaena mucicola. 23-24. Microcystis aeruginosa. 23. Colony with subcolonies. 24. Elongated colony. 25. Microcystis protocystis, cells with mucilaginous envelope (arrow). 26. Microcystis wesenbergii. 27. Radiocystis fernandoi. 28-29. Radiocystis cf. geminata. 28. Colony with subcolonies, trichome of Pseudanabaena mucicola (arrow). 29. Radially disposition of cells. 30-31. Sphaerocavum brasiliense. 32. Glaucospira sp. 33. Phormidium formosum. 34. Planktothrix agardhii. $\mathrm{Bar}=10 \mu \mathrm{m}$ 


\section{SPIRULINACEAE}

Glaucospira Lagerheim, 1892.

Glaucospira sp.

Figura 32

Tricomas móveis, regularmente espiralados, 22$27 \mu \mathrm{m}$ de distância entre as espiras, 65,6-73,4 $\mu \mathrm{m}$ de distância entre os ápices, bainha ausente, septos inconspícuos. Ápices não atenuados. Células $1,1 \mu \mathrm{m}$ diâm., conteúdo homogêneo, verde-azulado, pálido, grânulos irregularmente dispostos, sem aerótopos.

Este gênero é muito pouco conhecido sendo necessária a revisão, principalmente com material proveniente de cultura (Komárek \& Anagnostidis 2005). Porém, a mobilidade e forma espiralada dos tricomas, os septos inconspícuos e a presença de grânulos, tornam a população encontrada condizente com as características do gênero Glaucospira.

Material examinado: BRASIL. GoIÁs: Goiânia, lago Jaó, 11-XI-09, I.S. Nogueira \& W.A. Gama Jr. 1222 (UFG42230).

Distribuição geográfica no Estado de Goiás: primeira citação do táxon.

\section{PHORMIDIACEAE}

Phormidium Kützing ex Gomont, 1892.

Phormidium formosum (Bory ex Gomont) Anagnostidis \& Komárek, Arch. Hydrobiol. Suppl. 80(1-4) (Algolog. Stud. 50-53): 327. 1988.

Figuras 33

Tricomas móveis, retos ou sinuosos, longos, septos não constritos, finamente granulados ou lisos. Ápices levemente atenuados, retos ou curvos. Células isodiamétricas ou até duas vezes mais curtas que largas, 5,0-6,5 $\mu \mathrm{m}$ compr., 4,4-6,3 $\mu \mathrm{m}$ larg., conteúdo celular granuloso, sem aerótopos. Célula apical cônicoarredondada, sem caliptra.

Material examinado: BRASIL. GoIÁs: Goiânia, lago Jaó, 11-XI-09, I.S. Nogueira \& W.A. Gama Jr. 1222 (UFG42230), 11-XI-09, I.S. Nogueira \& W.A. Gama Jr. 1223 (UFG42231).

Distribuição geográfica no Estado de Goiás: primeira citação do táxon.

Planktothrix Anagnostidis \& Komárek 1988.

Planktothrix agardhii (Gomont) Komárek \& Anagnostids, Algolog. Stud. 50-53: 414. 1988.

Figura 34

Tricomas móveis, retos, septos não constritos. Ápices levemente atenuados. Células isodiamétricas até mais largas do que longas, 3,7-5,0 $\mu \mathrm{m}$ compr., 4-5 $\mu \mathrm{m}$ larg., aerótopos presentes. Célula apical levemente truncada, sem caliptra.

Planktothrix agardhii difere de P. isothrix por apresentar as células apicais truncadas e também tricomas que afilam em direção ao ápice (Komárek \& Komárková 2004), características encontradas na população estudada.

Material examinado: BRASIL. GoIÁs: Goiânia, lago Jaó, 19-IX-08, I.S. Nogueira 1214 (UFG40988), 19-IX-08, I.S. Nogueira 1215 (UFG40989).

Distribuição geográfica no Estado de Goiás: Caldas Novas: reservatório de Corumbá (Pivato et al. 2006); Goiânia: parque Ateneu (Nogueira et al. 2002); Luiz Alvez: lagoa do Japonês (Nogueira et al. 2002).

\section{OSCILLATORIACEAE}

Oscillatoria Vaucher ex Gomont, 1892.

Oscillatoria limosa Agardh ex Gomont, Ann. Sci. Nat. Bot., ser. 7, 16: 210. 1892.

Figuras 35-36

Tricomas móveis, retos, extensos, formando massas flutuantes, septos não constritos, frequentemente granulados. Ápices não ou levemente atenuados, retos ou levemente curvos. Células mais curtas que longas,

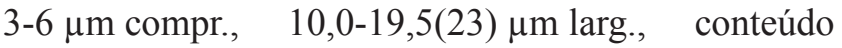
granuloso, sem aerótopo. Célula apical cilíndricoarredondada, sem caliptra.

Material examinado: BRASIL. GoIÁs: Goiânia, lago Jaó, 11-XI-09, I.S. Nogueira \& W.A. Gama Jr. 1222 (UFG42230), 11-XI-09, I.S. Nogueira \& W.A. Gama Jr. 1223 (UFG42231).

Distribuição geográfica no Estado de Goiás: primeira citação do táxon.

Oscillatoria perornata Skuja, Nova Acta R. Soc. Upsal., ser. 4, 14(5): 47. 1949.

Figura 37

Tricomas móveis, retos ou levemente ondulados, longos, formando massas flutuantes, septos levemente constritos, finamente granulados. Ápices atenuados, retos. Células mais curtas que longas, 2,7-4,5 $\mu \mathrm{m}$ compr., 10,0-13,5 $\mu \mathrm{m}$ larg., aerótopos presentes ou ausentes em partes do tricoma. Célula apical cônico-arredondada, sem caliptra.

Oscillatoria limosa e O. perornata ocorreram juntas, formando massas flutuantes na superfície do lago e diferem-se pela largura dos tricomas e presença de aerótopos na segunda. 
Material examinado: BRASIL. GoIÁs: Goiânia, lago Jaó, 11-XI-09, I.S. Nogueira \& W.A. Gama Jr. 1222 (UFG42230), 11-XI-09, I.S. Nogueira \& W.A. Gama Jr. 1223 (UFG42231).

Distribuição geográfica no Estado de Goiás: primeira citação do táxon.

\section{NOSTOCHOPHYCIDAE} NOSTOCACEAE

Cylindrospermopsis Seenayya \& Subba Raju, 1972. Cylindrospermopsis raciborskii (Woloszynska) Seenayya \& Subba Raju in Desikachary, Taxonomy and biology of blue-green algae, p.55. 1972.

Figura 38

Tricomas retos a sinuosos, 75-90 $\mu \mathrm{m}$ compr., septos levemente constritos. Ápices atenuados. Células cilíndricas, 5-6 $\mu \mathrm{m}$ compr., 3,5-4,5 $\mu \mathrm{m}$ larg., aerótopos presentes. Heterócitos cônico-arredondados, terminais em um e raramente em ambos os ápices, $8 \mu \mathrm{m}$ compr., $4 \mu \mathrm{m}$ larg. Acinetos não observados.

Os indivíduos analisados raramente apresentaram heterócitos e não foram observados acinetos. Essas características aproximaram a população ao gênero Raphidiopsis. Porém a semelhança entre a morfometria das células e dos tricomas entre os espécimes heterocitados e os não heterocitados levou a considerá-los como uma única população de C. raciborskii.

Material examinado: BRASIL. GoIÁs: Goiânia, lago Jaó, 19-IX-08, I.S. Nogueira 1214 (UFG40988), 19-IX-08, I.S. Nogueira 1215(UFG40989), 11-XI-09, I.S. Nogueira \& W.A. Gama Jr. 1223 (UFG42231), 11-XI-09, I.S. Nogueira \& W.A. Gama Jr. 1225 (UFG42233).

Distribuição geográfica no Estado de Goiás: Aruanã: lagoa Mata Coral e lagoa das Cangas (Nogueira et al. 2002); Caldas Novas: reservatório de Corumbá (Bazza 1998; Silva et al. 2001; Nogueira et al. 2002); Luiz Alves: localidade não indicada (Nogueira et al. 2002).

Dolichospermum (Bory ex Bornet \& Flahault) Wacklin, Hoffmann \& Komárek 2009.

Dolichospermum circinalis (Rabenhorst ex Bornet \& Flahault) Wacklin, Hoffmann \& Komárek. Fottea, 9(1): 61. 2009.

Figuras 39-40, 47C

Tricomas moniliformes, irregularmente espiralados, espiras $\quad 25-50 \mu \mathrm{m}$ alt., $\quad 70-120 \mu \mathrm{m}$ diâm. Bainha mucilaginosa estreita, difluente ou ausente. Células esféricas ou em forma de barril, 8-13 $\mu$ m diâm., aerótopos presentes. Heterócitos subesféricos, 8,3-10,5 $\mu \mathrm{m}$ diâm.
Acinetos elípticos, lisos, intercalares, 16,0-20,5 $\mu \mathrm{m}$ compr., 13,5-14,0 ㅆm diâm.

Deve-se atentar para tricomas retos de outras espécies que apresentam torções devido a fixação ou acondicionamento das amostras, dando a falsa impressão de uma espira. Isso foi observado durante a análise de material vivo e recém fixado.

Material examinado: BRASIL. GoiÁs: Goiânia, lago Jaó, 24-IV-07, I.S. Nogueira 1217 (UFG40991), 07-IV-01, I.S. Nogueira 1218 (UFG40992), 15-IV-06, I.S. Nogueira 1221 (UFG40995), 11-XI-09, I.S. Nogueira \& W.A. Gama Jr. 1223 (UFG42231).

Distribuição geográfica no Estado de Goiás: Caldas Novas: reservatório de Corumbá (como Anabaena circinalis, Silva et al. 2001).

Dolichospermum crassum (Lemmermann) Wacklin, Hoffmann \& Komárek. Fottea, 9(1): 61. 2009.

Figuras 41-42

Tricomas moniliformes, regularmente espiralados, espiras $\quad 30-55 \mu \mathrm{m}$ alt., $\quad 40-70 \mu \mathrm{m}$ diâm. Bainha mucilaginosa ampla, difluente, 16,3-27,7 $\mu$ m espes. Células em forma de barril, $8-14 \mu \mathrm{m}$ compr., 11-15 $\mu \mathrm{m}$ diâm., aerótopos presentes. Heterócitos esféricos, às vezes menor que a célula vegetativa, 9-15 $\mu \mathrm{m}$ diâm. Acinetos não observados.

Em relação as outras espécies com tricomas espiralados encontradas, $D$. crassum distingue-se por ter espiras sempre regulares e com dimensões maiores que as de $D$. spiroides e menores que as de $D$. circinalis.

Material examinado: BRASIL. GoiÁs: Goiânia, lago Jaó, 19-IX-08, I.S. Nogueira 1215 (UFG40989).

Distribuição geográfica no Estado de Goiás: primeira citação do táxon.

Dolichospermum flos-aquae ([Lyngbye] Brébisson ex Bornet \& Flahault) Wacklin, Hoffmann \& Komárek. Fottea, 9(1): 61. 2009.

Figuras 43-47B

Tricomas moniliformes, irregularmente espiralados a frouxamente curvos, Bainha mucilaginosa estreita, difluente ou ausente. Células esféricas até em forma de barril, 4-10 $\mu \mathrm{m}$ compr., 4,0-8,8 $\mu \mathrm{m}$ diâm., aerótopos presentes. Heterócitos esféricos a elipsóides, 13-20 $\mu \mathrm{m}$ compr., 6-13 $\mu \mathrm{m}$ diâm. Acinetos lisos, oblongos a elípticos, isolados, 13-21 $\mu \mathrm{m}$ compr., 5,7-12,5 $\mu \mathrm{m}$ diâm.

Nas amostras analisadas, os indivíduos de $D$. flos-aquae não apresentaram o acineto com um dos lados côncavos, sendo tipicamente oblongos, mas todas as 

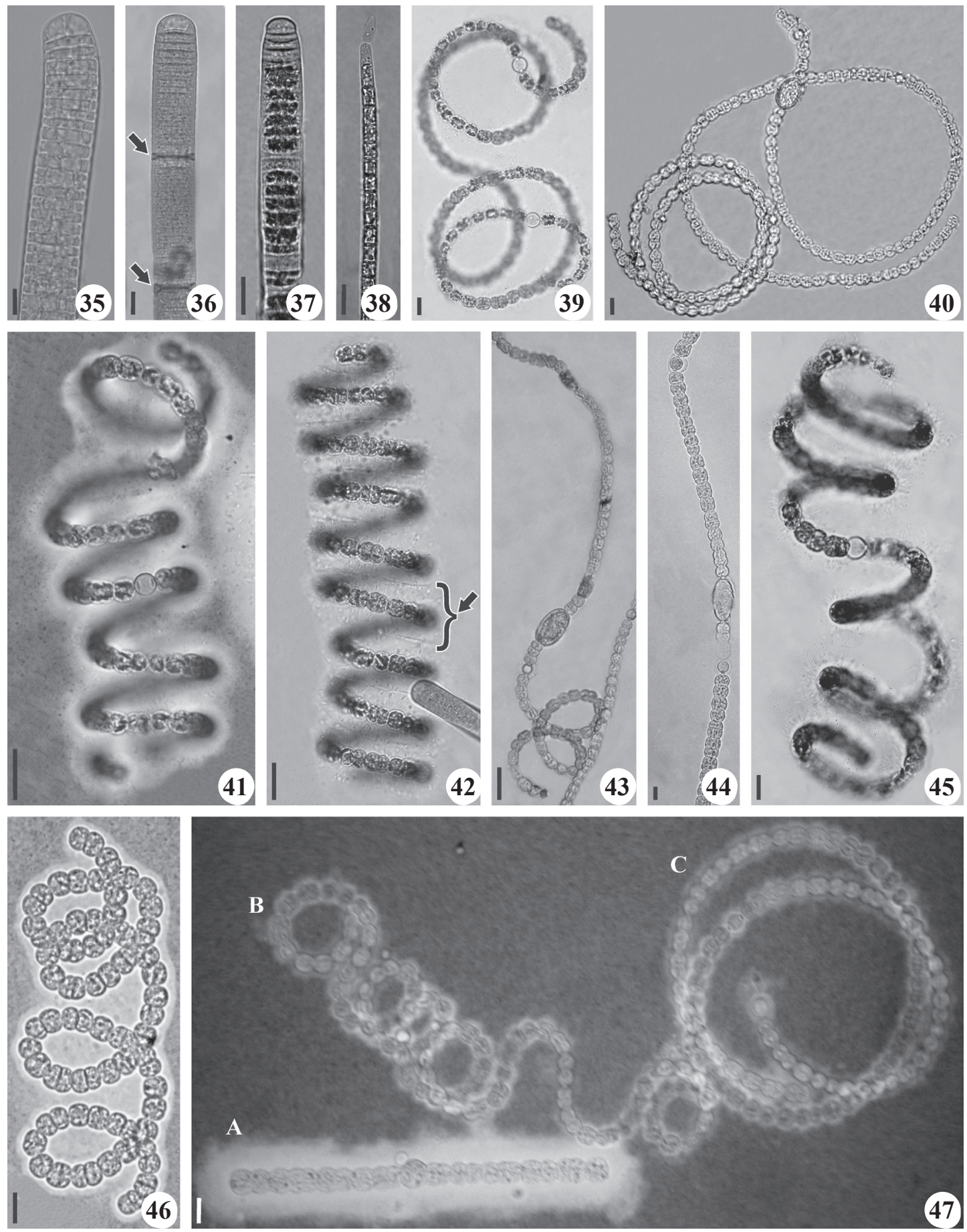

Figuras 35-47. 35-36. Oscillatoria limosa. 35. Ápice curvo. 36. Ápice reto e formação de necrídias (setas). 37. Oscillatoria perornata. 38. Cylindrospermopsis raciborskii. 39-40. Dolichospermum circinalis. 41-42. Dolichospermum crassum. 42. Envoltório mucilaginoso amplo (seta). 43. Dolichospermum flos-aquae. 44. Dolichospermum planctonicum. 45-46. Dolichospermum spiroides. 47. Diferentes espécies de Dolichospermum. 47A. Dolichospermum planctonicum. 47B. Dolichospermum flos-aquae. 47C. Dolichospermum circinalis. Barra $=10 \mu \mathrm{m}$

Figures 35-47. 35-36. Oscillatoria limosa. 35. Curved apex of trichome. 36. Straight end of trichome and formation of necridic cells (arrows). 37. Oscillatoria perornata. 38. Cylindrospermopsis raciborskii. 39-40. Dolichosperum circinalis. 41-42. Dolichospermum crassum. 42. Wide mucilaginous envelpe (arrow). 43. Dolichospermum flos-aquae. 44. Dolichospermum planctonicum. 45-46. Dolichospermum spiroides. 47. Different species of Dolichospermum. 47A. Dolichospermum planctonicum. 47B. Dolichospermum flos-aquae. 47C. Dolichospermum circinalis. Bar $=10 \mu \mathrm{m}$ 
outras características (bainha inconspícua, dimensões, forma e disposição das espiras no tricoma) foram condizentes com a descrição proposta por KomárkováLegnerová \& Eloranta (1992). Esses autores citaram a ocorrência deste táxon para ambientes eutróficos da Europa.

Material examinado: BRASIL. GoiÁs: Goiânia, lago Jaó, 19-IX-08, I.S. Nogueira 1214 (UFG40988), 15-IV-06, I.S. Nogueira 1221 (UFG40995).

Distribuição geográfica no Estado de Goiás: primeira citação do táxon.

Dolichospermum planctonicum (Brunnthaler) Wacklin, Hoffmann \& Komárek. Fottea, 9(1): 62. 2009.

Figuras 44-47A

Tricomas moniliformes, retos, longos. Bainha mucilaginosa ampla, difluente, até $30 \mu \mathrm{m}$ espes. Células esféricas, 9-15 $\mu \mathrm{m}$ diâm., aerótopos presentes. Heterócitos esféricos 7-10 $\mu \mathrm{m}$ diâm. Acinetos lisos, elípticos, solitários ou aos pares, 15-30 $\mu \mathrm{m}$ compr., 10-20 $\mu \mathrm{m}$ diâm.

Material examinado: BRASIL. GoiÁs: Goiânia, lago Jaó, 19-IX-08, I.S. Nogueira 1215 (UFG40989), 01-IX-04, I.S. Nogueira 1219 (UFG40993), 15-IV-06, I.S. Nogueira 1221 (UFG40995), 11-XI-09, I.S. Nogueira \& W.A. Gama Jr. 1222 (UFG42230), 11-XI-09, I.S. Nogueira \& W.A. Gama Jr. 1223 (UFG42231), 11-XI-09, I.S. Nogueira \& W.A. Gama Jr. 1225 (UFG42233).

Distribuição geográfica no Estado de Goiás: primeira citação do táxon.

Dolichospermum spiroides (Klebahn) Wacklin, Hoffmann \& Komárek. Fottea, 9(1): 62. 2009.

Figuras 45-46

Tricomas moniliformes, regular até desordenadamente espiralados, solitários a emaranhados, espiras 23-48 $\mu \mathrm{m}$ alt., 15,3-33,5 $\mu \mathrm{m}$ diâm. Bainha ampla, difluente, 13,4-17,2 $\mu \mathrm{m}$ espes. Células esféricas, subesféricas até em forma de barril, 6,5-10,0 $\mu \mathrm{m}$ diâm., aerótopos presentes. Heterócitos esféricos a subesféricos, 6-10 $\mu \mathrm{m}$ diâm. Acinetos não observados.

No material analisado a distância e regularidade das espiras, o diâmetro das células e dos heterócitos foram compatíveis com as descritas para os espécimes encontrados por Komárková-Legnerová \& Eloranta (1992), Sant'Anna et al. (2008) e Cybis et al. (2006).

Material examinado: BRASIL. GoIÁs: Goiânia, lago Jaó, 19-IX-08, I.S. Nogueira 1215 (UFG40989), 01-IX-04, I.S. Nogueira 1219 (UFG40993), 15-IV-06, I.S. Nogueira 1221 (UFG40995), 11-XI-09, I.S. Nogueira
\& W.A. Gama Jr. 1222 (UFG42230), 11-XI-09, I.S. Nogueira \& W.A. Gama Jr. 1223 (UFG42231), 11-XI-09, I.S. Nogueira \& W.A. Gama Jr. 1225 (UFG42233).

Distribuição geográfica no Estado de Goiás: primeira citação do táxon.

Durantes os anos de 2003 a 2006, o lago Jaó apresentou-se entre constantes florações, cujas espécies predominantes foram de cianobactérias (figura 48), variando em 100.000 indivíduos $\mathrm{mL}^{-1}$ a 200.000 indivíduos $\mathrm{mL}^{-1}$. Nos anos de 2003 a 2005 ocorreram predomínios de florações de espécies de Dolichospermum circinalis e D. spiroides. Em 2006 predominaram espécies dos gêneros Microcystis e Radiocystis. Todas as espécies dominantes e outras que também ocorreram durante este estudo, totalizando-se 13, são consideradas potencialmente tóxicas (Sant'Anna et al. 2008).

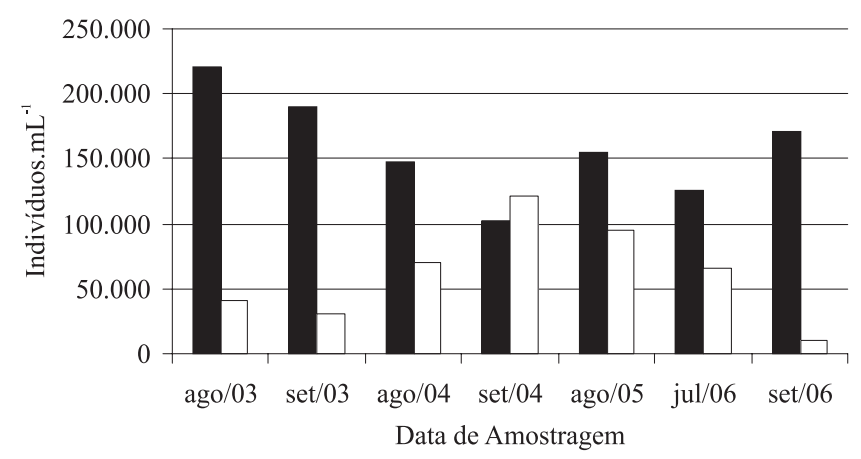

Figura 48. Densidades populacionais de cianobactérias (barras escuras) e algas em geral (barras claras) registradas em amostragens aleatórias no lago Jaó (Goiânia, GO) entre 2003 e 2006.

Figure 48. Population densities of cyanobacteria (colored bars) and algae in general (white bars), way recorded in random samples in Jaó Lake (Goiânia, GO) between 2003 and 2006.

Dos 31 táxons de cianobactérias identificados, 21 estão sendo citados como primeiro registro para o Estado de Goiás. Na amostragem de 2009 observaram-se os maiores valores de riqueza específica, tendo sido esse período o único amostrado durante a estação chuvosa. Nessa coleta, o lago estava em processo de esvaziamento e por isso possuía baixa profundidade, o que associado às chuvas, proporcionou a coleta da comunidade metafítica. Por esse motivo, espécies como Coelosphaerium limnocolum, Limnothrix guttulata, Phormidium formosum e Oscillatoria limosa, originalmente descritas como metafíticas ou bentônicas, foram registradas neste estudo. 
Várias espécies de ocorrência para ambientes temperados foram encontradas. Todavia, a identificação só foi confirmada quando as populações eram expressivas e apresentavam as características diacríticas originalmente descritas para as espécies. Além disso, ainda são escassos os estudos para a região central do Brasil e várias espécies podem ter uma maior distribuição do que aquela já documentada, o que pode ser comprovado com as novas citações para o Estado de Goiás aqui apresentadas.

Agradecimentos - À Dra. Célia Leite Sant'Anna, pela gentileza em confirmar algumas espécies deste trabalho. Aos dois Assessores deste trabalho pelas enriquecedoras correções e sugestões. Ao Conselho Nacional de Desenvolvimento Científico e Tecnológico (CNPq), pela concessão de bolsa de Iniciação Científica a Watson Arantes Gama Júnior.

\section{Referências bibliográficas}

APELDOORN, M.E. VAN, EGMOND, H.P. VAN, SPEIJERS, G.J.A. \& BAKKER, G.J.I. 2007. Toxins of Cyanobacteria. Molecular Nutrition \& Food Research 51:7-60.

BAZZA, E.L. 1998. Flutuações na estrutura da comunidade fitoplanctônica durante o período de enchimento do reservatório de Corumbá (GO). Monografia Ciências Biológicas, Universidade Estadual de Maringá, Paraná.

BICUDO, C.E.M. \& MENEZES, M. 2006. Gêneros de algas de águas continentais do Brasil: chave para identificação e descrições. 2ª ed., Rima, São Carlos.

BITTENCOURT-OLIVEIRA, M.C., MOURA, A.N., OLIVEIRA, M.C. \& MASSOLA JR., N.S. 2009. Geitlerinema species (Oscillatoriales, Cyanobacteria) revealed by cellular morphology, ultrastructure, and DNA sequencing. Journal of Phycology 45:716-725.

BRANDÃO, D. \& KRAVCHENKO, A. 1997. A biota do Campus Samambaia: história, situação e perspectivas. Abeu/Cegraf-Ufg, Goiânia.

CAMPOS, I.F.P. \& MACEDO-SAIDAH, F.F. 1990. Flórula da represa da escola de agronomia da Universidade Federal de Goiás, Goiânia, Goiás, Brasil. In Anais do XXXVI Congresso Nacional de Botânica. Ibama/Sbb, Brasília, p.839-857.

CAMPOS, I.F.P., RIZZO, J.A. \& PEREIRA, H.D. 1990. Plano de Coleção de algas do Estado de Goiás. In Flora do Estado de Goiás: Criptógamos. (I.F.P. Campos, ed.). Abeu/Cegraf-Ufg, Goiânia, v.1, p.1-18.

CLESCERI, L.S., GREENBERG, A.E. \& TRUSSELL, R.R. 1992. Métodos normalizados para el analisis de águas potables y residuales. Ediciones Diaz de Santos S.A/ American Public Health Association, Madrid.
CONTIN, L.F. \& OLIVEIRA, R.J.M. 1993. Diatomáceas. In Flora do Estado de Goiás: Criptógamos. (I.F.P. Campos, ed.). Abeu/Cegraf-Ufg, Goiânia, v.2, p.1-35.

CRISPIM, W.M.C., REBOUÇAS-BESSA, M.R. \& OSÓRIO, N.B. 1992. Avaliação do comportamento de um sistema de lagoa de estabilização em série tratando esgotos domésticos - Região Centro-Oeste do Brasil. In V Simpósio Luso-Brasileiro de Engenharia Sanitária Ambiental. Sesa, Lisboa, p.163-173.

CYBIS, L.F.A., BENDATI, M.M., MAIZONAVE, C.R.M., WERNER, V.R. \& DOMINGUES, C.D. 2006. Manual para estudos de cianobactérias planctônicas em mananciais de abastecimento público: caso da represa lomba do sabão e lago Guaíba. Rio Grande do Sul, Porto Alegre, v.1, p.1-64.

DESIKACHARY, T.V. 1959. Cyanophyta. Indian Council of Agricultural Research, New Delhi.

DROUET, F. 1957. The Machris Brasilian expedition, Botany: Cyanophyta. Contributions in Science, Los Angeles County Museum 5:1-2.

GEITLER, L. 1932. Cyanophyceae. In Rabenhorst's Kryptogamenflora von Deutschland, Österreich und der Schweiz (R. Kolkwitz, ed.). Akademische, Verlagsgesellschaft, Leipzig, v.14, p.1-1195.

GOLTERMAN, H.L. CLYMO, R.S. \& OHNSTAD, M.A.M. 1978. Methods for physical and chemical analysis of freshwaters. IBP Handbook 8. $2^{\text {nd }}$ ed., Blackwell, Oxford.

HOFFMANN, L. 1996. Geographic distribution of freshwater blue-green algae. Hydrobiologia 336:33-40.

HOFFMANN, L., KOMÁREK, J. \& KAŠTOVSKÝ, J. 2005. System of cyanoprokaryotes (cyanobacteria) - state in 2004. Algological Studies 117:95-115.

KITAMURA, P.C., LOPES, R.B., CASTRO-JUNIOR, F.G. \& QUEIROZ, J.F. 1999. Avaliação ambiental e econômica dos lagos de pesca esportiva na bacia do Rio Piracicaba. Boletim de Indústria Animal 56:95-107.

KOMÁREK, J. 1991. A review of water-bloom forming Microcystis species, with regard to populations from Japan. Algological Studies 64:115-127.

KOMÁREK, J. \& ANAGNOSTIDIS, K. 1989. Modern approach to the classification system of Cyanophytes, 4: Nostocales. Algological Studies 56:247-345.

KOMÁREK, J. \& ANAGNOSTIDIS, K. 1998. Cyanoprokaryota, 1: Chroococcales. In Süsswasserflora von Mitteleuropa (H. Ettl, G. Gärtner, H. Heynig \& D. Möllenhauer, eds.). Gustav Fischer, Stuttgart, v.19, p.1-548.

KOMÁREK, J. \& ANAGNOSTIDIS, K. 2005. Cyanoprokaryota, 2: Oscillatoriales. In Süsswasserflora von Mitteleuropa (B. Büdel, L. Krienitz, G. Gärtner \& M. Schagerl, eds.). Elsevier Spektrum Akademischer Verlag, München, v.19, p.1-759.

KOMÁREK, J. \& CRONBERG, G. 2001. Some chroococcalean and oscillatorialean Cyanoprokaryotes from southern African lakes, ponds and pools. Nova Hedwigia 73:129-160. 
KOMÁREK, J. \& KOMARKOVÁ, J. 2002. Review of the European Microcystis - morphospecies (Cyanoprokaryotes) from nature. Czech Phycology 2:1-24.

KOMÁREK, J. \& KOMARKOVÁ, J. 2004. Taxonomic review of the cyanoprokaryotic genera Planktothrix and Planktothricoides. Czech Phycology 4:1-18.

KOMÁRKOVÁ-LEGNEROVÁ, J. \& ELORANTA, P. 1992. Planktic blue-green algae (Cyanophyta) form Central Finland (Jyväskylä region) with special reference to the genus Anabaena. Algological Studies 67:103-133.

KUBTIZA, F. 2003. Qualidade da água no cultivo de peixes e camarões. $1^{\underline{a}}$ ed., Jundiaí, São Paulo.

LOBO, E. \& LEIGHTON, G. 1986. Estructuras comunitarias de las fitocenosis planctonicas de los sistemas de desembocaduras de rios y esteros de la zona central de Chile. Revista de Biologia Marina y Oceanografia 22:1-29.

LUND, J.W.G., KIPLING, C. \& LECREN, E.D. 1958. The inverted microscope method of estimating algal number and the statistical basis of estimating by counting. Hydrobiologia 11:143-170.

MAGALHÃES, V.F., SOARES, R.M. \& AZEVEDO, S.M.F.O. 2001. Microcystin contamination in fish from the Jacarepaguá Lagoon (Rio de Janeiro, Brazil): ecological implication and human health risk. Toxicon 39:1077-1085.

MATSUZAKI, M., MUCCI, J.L.N. \& ROCHA, A.A. 2004. Comunidade fitoplantônica de um pesqueiro na cidade de São Paulo. Revista Saúde Pública 38:679-686.

MCGREGOR, G.B., FABBRO, L.D. \& LOBEGEIGER, J.S. 2007. Freshwater planktic Chroococcales (Cyanoprokaryota) from North-Eastern Australia: a morphological evaluation. Nova Hedwigia 84:299-331.

MOHAMED, Z.A. 2008. Toxic cyanobacteria and cyanotoxins in public hot springs in Saudi Arabia. Toxicon 51:17-27.

NARDINI, M.J. \& NOGUEIRA, I.S. 2008. O processo antrópico de um lago artificial e o desenvolvimento da eutrofização e florações de algas azuis em Goiânia. Estudos 35:23-52.

NASCIMENTO-BESSA, M.R.R.N. \& SANTOS, C.R.A. 1995. Fitoplâncton e fatores fisíco-químicos em Lagos do Bosque dos Buritis no Município de Goiânia, GoiásBrazil. In Anais do Word-wide symposium pollution in large cities, science and techonology for planning environmental quality. Abes/Andis/Aidis, Venice/ Padora, p.17-26.

NOGUEIRA, I.S. \& LEANDRO-RODRIGUES, N.C. 1999. Algas planctônicas do lago do Jardim Botânico Chico Mendes, Goiânia, GO: considerações taxonômicas e ecológicas. Revista Brasileira de Biologia 59:377-395.

NOGUEIRA, I.S., NABOUT, J.C., OLIVEIRA, J.E. \& SILVA, K.D. 2008. Diversidade (alfa, beta e gama) da comunidade fitoplanctônica de quatro lagos artificiais urbanos do município de Goiânia, GO. Hoehnea 35:219-233.
NOGUEIRA, I.S., SILVA, K.D., NABOUT, J.C. \& BESSA, M.R.R.N. 2002. Cyanobacteria potencialmente tóxicas de diferentes mananciais do Estado de Goiás - Brasil. In Anais do X Simpósio Luso-Brasileiro de Engenharia Sanitária e Ambiental. Tema 5 - Gestão Ambiental e Saúde Pública. (J.M.P. Vieira, A.C. Rodrigues \& A.C.C. Silva, coord). Apesb/Aprh/Abes, Braga, Portugal v.1, p.1-14.

PIVATO, B.M., TRAIN, S. \& RODRIGUES, L.C. 2006. Dinâmica nictemeral das assembléias fitoplanctônicas em um reservatório tropical (reservatório de Corumbá, Estado de Goiás, Brasil), em dois períodos do ciclo hidrológico. Acta Scientiarum Biological Sciences 28:19-29.

PRESCOTT, G.W. 1957. The Machris Brazilian expedition, Botany: Chlorophyta, Euglenophyta. Contributions in Science, Los Angeles County Museum 11:1-29.

SANEAGO (SANEAMENTO DE GOIÁS S.A). 1996. Relatório do Monitoramento do Ribeirão João Leite - Período 94-95. Saneamento de Goiás S.A, Goiânia.

SANT'ANNA, C.L. \& AZEVEDO, M.T.P. 2000. Contribution to the knowledge of potentially toxic Cyanobacteria from Brazil. Nova Hedwigia 71:359-385.

SANT'ANNA, C.L., AZEVEDO, M.T.P., SENNA, P.A.C., KOMÁREK, J. \& KOMÁRKOVÁ, J. 2004. Planktic Cyanobacteria from São Paulo State, Brazil: Chroococcales. Revista Brasileira de Botânica 27: 213-227.

SANT'ANNA, C.L., AZEVEDO, M.T.P., WERNER, V.R., DOGO, C.R., RIOS, F.R. \& CARVALHO, L.R. 2008. Review of toxic species of Cyanobacteria in Brazil. Algological Studies 126:251-265.

SANT'ANNA, C.L., SILVIA, S.M., CARVALHO, M.C., GEMELGO, M.P. \& AZEVEDO, M.T.P. 2007. Planktic Cyanobacteria from upper Tietê basin reservoirs, SP, Brazil. Revista Brasileira de Botânica 30:1-15.

SILVA, C.A., TRAIN, S. \& RODRIGUES, L.C. 2001. Estrutura e dinâmica da comunidade fitoplanctônica a jusante e montante do reservatório de Corumbá, Caldas Novas, Estado de Goiás, Brasil. Acta Scientiarum Biological Sciences 23:283-290.

TUNDISI, J.G. \& MATSUMURA-TUNDISI, T. 2008. Limnologia. Oficina de Textos, São Paulo.

ÜHELINGER, V. 1964. Étude statistique des methodes de dénombrement planctonique. Archives des Sciences 17:121-223.

UTERMÖHL, H. 1958. Zur Vervollkommnung der quantitativen Phytoplankton-Methodik. Mitteilungen Internationale Vereinigung Theoretische und Angewandte Limnologie 9:1-38.

VERAART, A.J., ROMANÍ, A.M., TORNE'S, E. \& SABATER, S. 2008. Algal response to nutrient enrichment in forested oligotrophic stream. Journal of Phycology 44:564-572. 
VOLLENWEIDER, R.A. 1974. A manual on methods for measuring primary production in aquatic environments. IBP Handbook 12. $2^{\text {nd }}$ ed., Blackwell Scientific Publications, London.
WACKLIN, P., HOFFMANN, L. \& KOMÁREK, J. 2009. Nomenclatural validation of the genetically revised cyanobacterial genus Dolichospermum (Ralfs ex Bornet et Flahault) comb. nova. Fottea 9:59-64. 